\title{
Impregnation of Carbonate Rock with Bituminous Compounds. III. Thermophysical Properties of the Impregnation Material
}

\author{
Zufar I. Zaripov1, Ilgiz R. Gabitov1, Ruslan R. Nakipov', Farid M. Gumerov1, \\ Mansur I. Farakhov' ${ }^{2}$, Vener F. Khayrutdinov ${ }^{2}$ \\ ${ }^{1}$ Federal State Budgetary Educational Institution of Higher Professional Education "Kazan National Research \\ Technological University", Kazan, Russian Federation \\ ${ }^{2}$ Limited Liability Company Engineering, Promotional Center “Inzhekhim”, Kazan, Russian Federation \\ Email:gum@kstu.ru
}

Received 22 October 2015; accepted 20 December 2015; published 23 December 2015

Copyright (C) 2015 by authors and Scientific Research Publishing Inc.

This work is licensed under the Creative Commons Attribution International License (CC BY). http://creativecommons.org/licenses/by/4.0/

c) (i) Open Access

\section{Abstract}

The investigation on thermodynamic properties (density $\rho$, viscosity $v$ ) of heavy oil has been carried out in the temperature range $298-363 \mathrm{~K}$ at pressure $0.098 \mathrm{MPa}$, and thermal expansion coefficient $\alpha_{p}$ at pressures up to $49 \mathrm{MPa}$. The results of specific heat measurements of oil and oil products are presented at pressures up to $29 \mathrm{MPa}$ and temperatures up to $613 \mathrm{~K}$ for heavy oil and temperature range of $323-473 \mathrm{~K}$ at atmospheric pressure for oil products. Thermal effects occurring during the processing of crude oil have been investigated. According to the obtained values of thermal expansion coefficients, density of the oil has been calculated for pressures up to $49 \mathrm{MPa}$.

\section{Keywords}

Heavy Crude Oil, Mixtures, Specific Heat, Thermal Expansion Coefficient, Density, Viscosity, Heat Effect

\section{Introduction}

The current trend in the refining industry is the use of heavy crude oils. Because of the higher content of heteroatoms, metals and asphaltenes, as well as due to greater amount of non-separable hydrocarbons, it is more difficult to process this oil [1]-[3].

Against this background, the problems of rational use and processing of hard recoverable reserves, such as highly-viscous oils and natural bitumen, become more urgent. These problems cannot be solved without the im- 
plementation of modern production technologies, such as steam-thermal (Cyclic Steam Stimulation-CSS [1], Steam-Assisted Gravity Drainage-SAGD [4]), cold production (Cold Heavy-Oil Production with SandCHOPS [5]), technologies based on the use of solvents and catalysts [6]-[8], as well as the implementation of hydrocarbon refining technologies [9]-[27]. Nowadays one of the promising, environmentally friendly methods for production and refining of highly-viscous oils and natural bitumen is the use of supercritical fluid (SCF) technologies [28]-[30].

The problems of rational use and refining of scavenger heavy oil and natural bitumen cannot be solved without the implementation of a wide range of modern extraction and processing technologies [4]-[30].

Highly viscous oil is a dispersed medium in which asphaltenes are dispersed into hydrocarbons with a lower molecular weight. This entire medium is stabilized by poly-nuclear aromatic compounds and resins constituting the solvate shell [31]. The dispersed medium is unstable. Under the influence of various factors (temperature, pressure), the medium is a subject to various phase transformations including precipitation and dissolution [31][33].

Phase behavior of heavy oils and bitumen is the necessary initial data for the development and design of technological processes and activities associated with their production, transportation and processing of oil. These materials, as well as many other fluids industry is interested in, are opaque to visible light and their phase behavior cannot be studied using optical cells, and even X-ray Tomography [33]. Only the use of different methods of analysis will allow identifying the characteristics of their phase behavior. Differential Scanning Calorimetry (DSC) is a sensitive method for the detection and evaluation of phase transitions [34]-[39].

Thus, designing and optimization of oil refining technological processes require data on phase behavior and thermal properties (density, viscosity and composition) of both oils/oil fractions and their mixtures with solvents. There are many researches in this area, including investigations on phase equilibrium [37]-[42], compositions and properties [42]-[52].

This investigation is a part of the big research [53], where heavy oil from Ashalchinskoye accumulation (Republic of Tatarstan, Russian Federation) has been selected as the object of the study, for which there are available data on component and hydrocarbon compositions, and structural characteristics [43]-[48]. The aim of this study is to obtain new data on composition and properties of the described heavy oil and its derivatives necessary to analyze the influence of thermodynamic parameters on their phase state.

\section{Experimental Part}

\subsection{Materials, Apparatus and Investigation Methods}

The objects of the investigation are: highly viscous oil from Ashalchinskoye accumulation (Republic of Tatarstan, Russian Federation) and products of its refining: deasphaltizate, bitumen; asphalt. The deasphaltizate has been gained from the heavy oil residue relating to refining process of highly viscous oil with the use of thermal-steam method [23] and propane/butane deasphaltizing [24].

$\mathrm{X}$-ray fluorescence analysis has been applied to determine the elemental composition. The measurements have been carried out using energy-dispersive X-ray fluorescence spectrometer EDX-800HS2 produced by "Shimadzu" (Japan) with the implementation of semi-quantitative method. Measurement conditions: Rh-anode tube (50 watts); voltage: $50 \mathrm{kV}, 15 \mathrm{kV}$; current: auto; medium-Helium; diameter measured: $10 \mathrm{~mm}$; measuring time: 100 seconds. Measurements of the samples have been carried out in the range of Ti-U (0.00 - $40.00 \mathrm{keV})$, Na-Sc $(0.00-4.40 \mathrm{keV})$.

The investigation on thermodynamic properties (density $\rho$, viscosity $v$ ) of the heavy oil has been held in the temperature range of $298-363 \mathrm{~K}$ at pressure $0.098 \mathrm{MPa}$, whereas thermal expansion coefficient $\alpha_{t}$ at pressures up to $49 \mathrm{MPa}$. For the measurement of thermal expansion coefficient $\alpha_{t}$ the experimental apparatus has been used that implements the method of heat-conducting calorimeter [54]. Calculation formulas of the method and the measurement procedure are described in details in [55]-[57]. Reliability of the experimental data on $\alpha_{p}$ is confirmed by control (reference) measurements of chemically-pure substances such as hexane $\left(n_{D}^{20}=1.3749\right.$; $\left.\rho_{4}^{25}=659.1 \mathrm{~kg} \cdot \mathrm{m}^{-3}\right)$ [54], and butyl alcohol $\left(n_{D}^{20}=1.3995 ; \rho_{4}^{20}=809.5 \mathrm{~kg} \cdot \mathrm{m}^{-3}\right)$ [57] [58]. For the measurement of isobaric heat capacity at pressures up to $50 \mathrm{MPa}$ in the temperature range of $273-673 \mathrm{~K}$ the upgraded scanning calorimeter ITS-400 has been used.

Density $\rho$ at atmospheric pressure has been measured by glass pycnometer with the volume of $10 \mathrm{ml}$ in accordance with GOST 7465-67 [59] [60], whereas at high-pressures the metal pycnometer has been used with the 
volume of $2.2 \mathrm{ml}$ [57]. For the viscosity measurement there have been used capillary viscometers VPG-1 [61]. The refractive index $n_{D}^{20}$ has been determined by IRF-22 refractometer [62] [63]. Temperature control of pyknometers and viscometers has been carried out by ultra-thermostat U-10 and electronic thermostat by Huber with an accuracy of better than $\pm 0.02 \mathrm{~K}$. Weighting was performed by scales brand VLA-200 and VLTE-150 with an accuracy of $\pm 0.0001 \mathrm{~g}$ and $\pm 0.001 \mathrm{~g}$, respectively.

\section{Results and Discussion}

\subsection{Elemental Composition of Oil-Products}

On the basis of structural analysis (Table 1) and the measurements of density, refractive index and kinematic viscosity of the oil (Figure 1, Table 2), such molecular characteristics as molecular weight and similarity criterion $\alpha$ have been calculated (Table 3).

The calculation of the molecular weight has been carried out using approximation equations [64]:

$$
\begin{gathered}
M W=250 \cdot \sqrt{\left(\lg v_{20}+0.8\right)} \\
\lg (M W-60)=0.39+2.52 \cdot\left(\rho_{4}^{20}\right)^{2}
\end{gathered}
$$

where $v_{20}$ and $\rho_{4}^{20}$-values of kinematic viscosity and density at temperature $t=20^{\circ} \mathrm{C}$. According to the Table 1. The results of elemental analysis of the oil-product samples.

\begin{tabular}{cccccc}
\hline No. & Sample name & C, \% & H, \% & N, \% & S and O, \% \\
\hline 1 & Oil (sample No.1) & 82.78 & 12.56 & 0.47 & 4.19 \\
2 & Deasphaltizate & 83.87 & 12.78 & 0.42 & 2.93 \\
3 & Asphalt & 83.53 & 9.75 & 0.91 & 5.81 \\
4 & Bitumen & 83.72 & 12.06 & 0.61 & 3.61 \\
\hline
\end{tabular}

\begin{tabular}{|c|c|c|c|c|c|}
\hline Sample name & Sample No. & $\begin{array}{c}\text { Temperature } t \text {, } \\
{ }^{\circ} \mathrm{C}\end{array}$ & $\begin{array}{l}\text { Density } \rho \text {, } \\
\mathrm{kg} \cdot \mathrm{m}^{-3}\end{array}$ & $\begin{array}{c}\text { Kinematic viscosity } \\
v, \mathrm{cSt}\end{array}$ & $\begin{array}{c}\text { Average molecular } \\
\text { weight }\end{array}$ \\
\hline \multirow{3}{*}{ Oil } & 1 & 20 & 953.1 & & 417 \\
\hline & 2 & 20 & 955.6 & 3102.5 & 467 \\
\hline & 3 & 20 & 963 & 2268 & 457 \\
\hline \multirow{4}{*}{$\begin{array}{l}\text { Synthetic crude oil } \\
\text { (SCO) }\end{array}$} & 1 & 20 & 898 & & 204.3 \\
\hline & 2 & 20 & 892 & 16.4 & 233.1 \\
\hline & 3 & 20 & 935 & 39.9 & 324.4 \\
\hline & 4 & 20 & 919 & 13.1 & 268.5 \\
\hline \multirow{5}{*}{ Oil } & & 20 & 955.6 & 3102.5 & \\
\hline & & 40 & 943.6 & 587.3 & \\
\hline & 2 & 60 & 931.6 & 168.8 & \\
\hline & & 80 & 919.6 & 65.3 & \\
\hline & & 90 & 913.6 & 44.2 & \\
\hline
\end{tabular}

Table 2. Smoothed-up data on density and viscosity of the oil samples.

\begin{tabular}{|c|c|c|c|c|}
\hline Parameter & Oil & Deasphaltizate & Asphalt & Bitumen \\
\hline Similarity criterion by Shaw [38] [65]-[67] $\alpha, \mathrm{mol}^{-\mathrm{g}^{-1}}$ & 0.1956 & 0.1987 & 0.1706 & 0.1920 \\
\hline
\end{tabular}

Table 3. Molecular characteristics of the investigated oil-products. 
characteristics, the oil samples correspond to a fraction of bituminous oil with average molecular weight of 465 $\mathrm{g} \cdot \mathrm{mol}^{-1}$. Viscosity index VI $=150$ [68]. During the calculation of the similarity criterion the following formula has been applied [65]-[67]:

$$
\alpha=\frac{\sum_{i=1}^{n} \omega_{i} / M_{i}}{\sum_{i=1}^{n} \omega_{i}}
$$

where $M_{i}$ and $\omega_{i}$-molecular weight $\left(\mathrm{g} \cdot \mathrm{mol}^{-1}\right)$ and weight percentage of a chemical element in the compound; $n$-number of elements in the compound.

The obtained data on molecular and structural characteristics have been implemented for the analysis of experimental data on heat capacity.

\subsection{Heat Capacity}

Control measurements of the apparatus have been carried out on two samples: stearic acid (chemically pure grade) at atmospheric pressure and butyl alcohol at pressures up to $30 \mathrm{MPa}$ [69] [70]. Deviations from [58] [71] [72] for these substances do not exceed $2 \%-3 \%$. Confidence limits of the total measurement error of $C_{p}$ at $P=$ 0.95 are less than $2 \%$. Heat capacity behavior $C_{p}=f(P, T)$ of the oil-products are presented in Figures 1-6.

For the oil-product samples (Figure 1, Figure 4 and Figure 5) some common patterns can be noted, typical for phase transitions. These changes relate primarily to the composition of oil-products [43]-[47]. Thus, according to [45]-[48] data on hydrocarbon, structural-group and component analysis for a fraction of $350^{\circ} \mathrm{C}-450^{\circ} \mathrm{C}$, which corresponds to the characteristics of the oil investigated, paraffin-naphthene compounds are represented mainly by solid alkanes and naphthenic hydrocarbons with various numbers of rings, while the aromatic hydrocarbons consist primarily of polycyclic naphthene-aromatic structures with short side chains. This is also confirmed by chromatograms from the results of [45]. Thus $350^{\circ} \mathrm{C}-450^{\circ} \mathrm{C}$ oil fraction contains some n-alkanes C26-C31, also a large number of high-molecular pentacyclic structures-hopanes C27-C35 is noted, where adianthan C29 and hopane C30 have the highest concentrations. Thus, the presence of solid phase in the composition of the oil and its refinery-products causes a particular behavior of the heat capacity (Figure 1, Figure 4

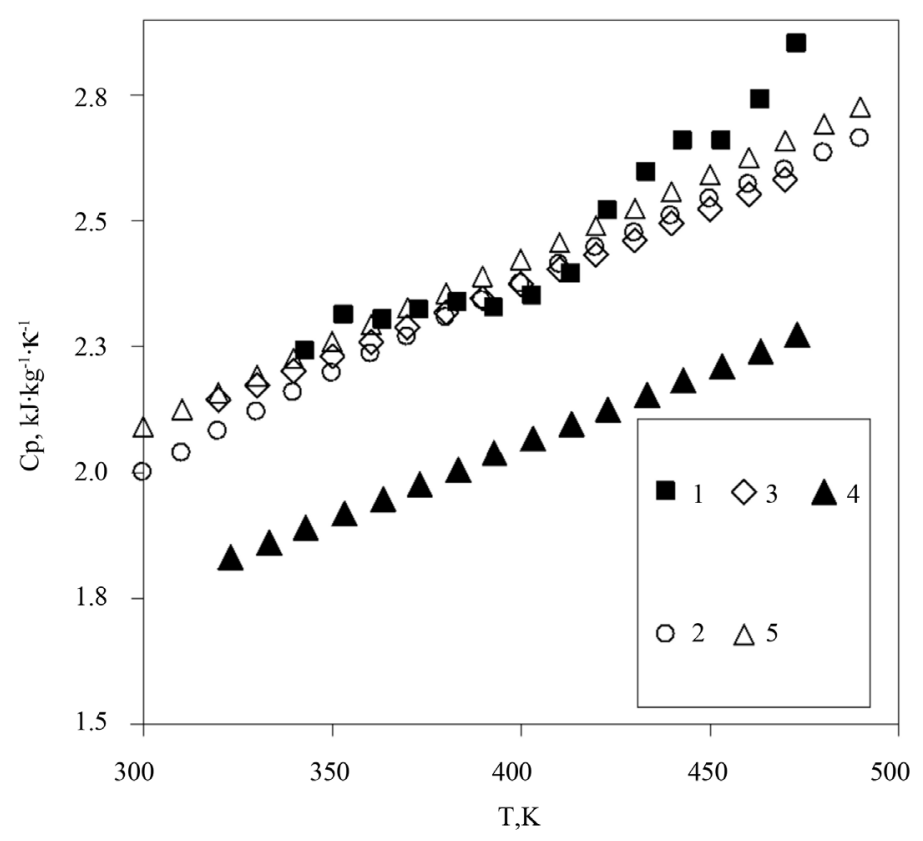

Figure 1. Comparison of the experimental and calculated heat capacity values of the oil (Sample No.1): 1-experiment; 2-calculation according to [73]; 3-calculation according to [65]-[67]; 4—calculation according to [52]. 


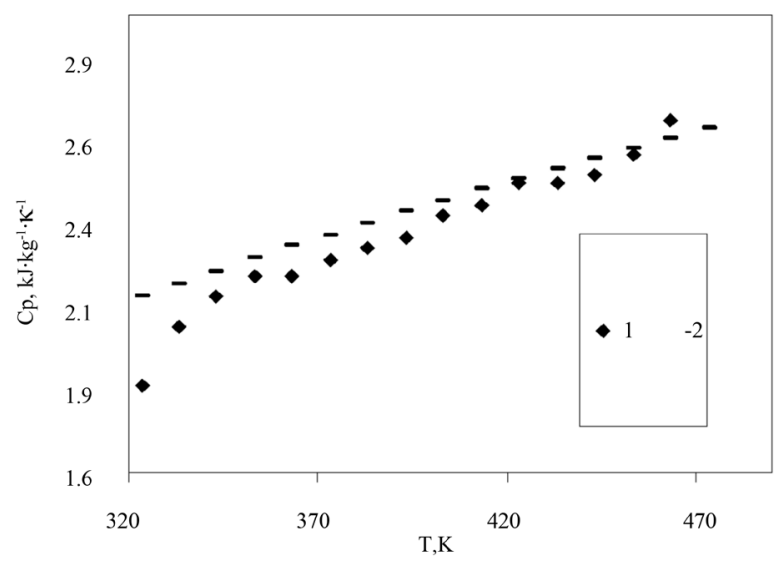

Figure 2. Heat capacity of the oil (sample No.2): 1-experiment; 2 - calculation according to [65]-[67].

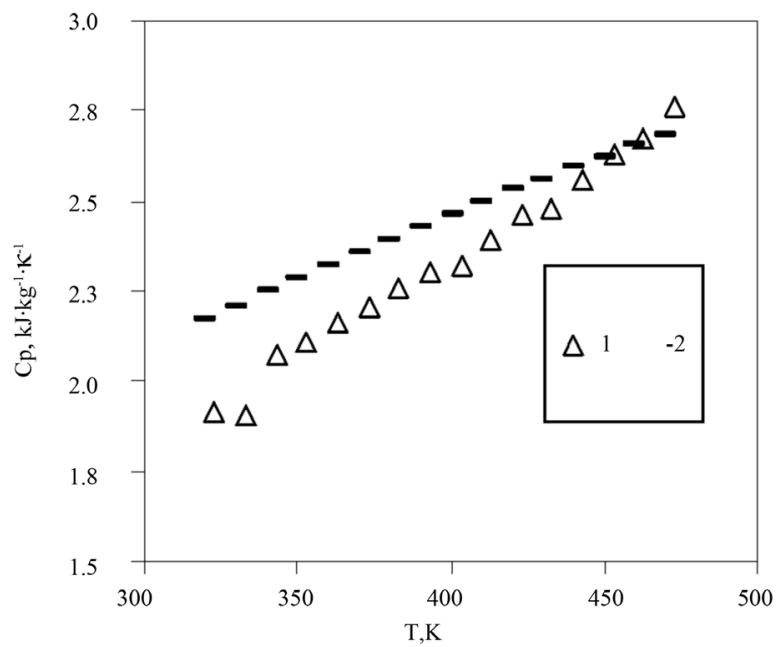

Figure 3. Heat capacity of deasphaltizate: 1-experiment; 2-calculation according to [65]-[67].

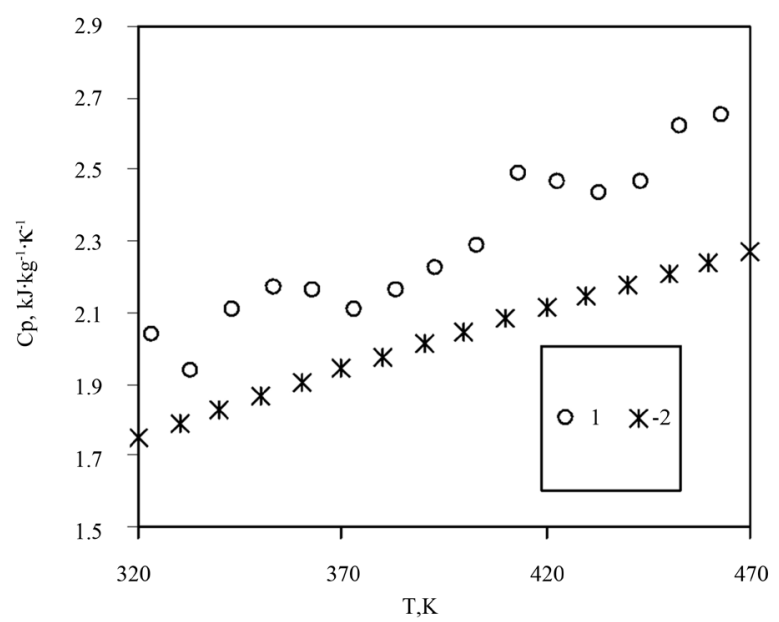

Figure 4. Heat capacity of asphalt: 1-experiment; 2-calculation according to [65]-[67]. 


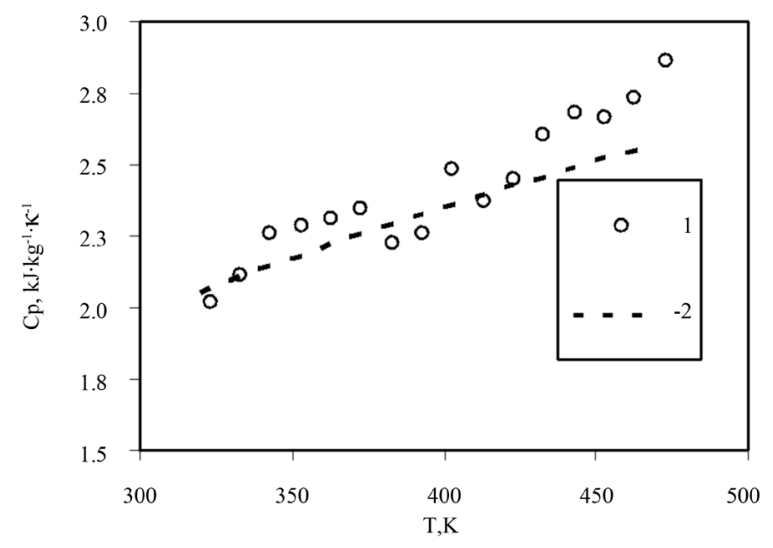

Figure 5. Heat capacity of bitumen: 1-experiment; 2calculation according to [65]-[67].

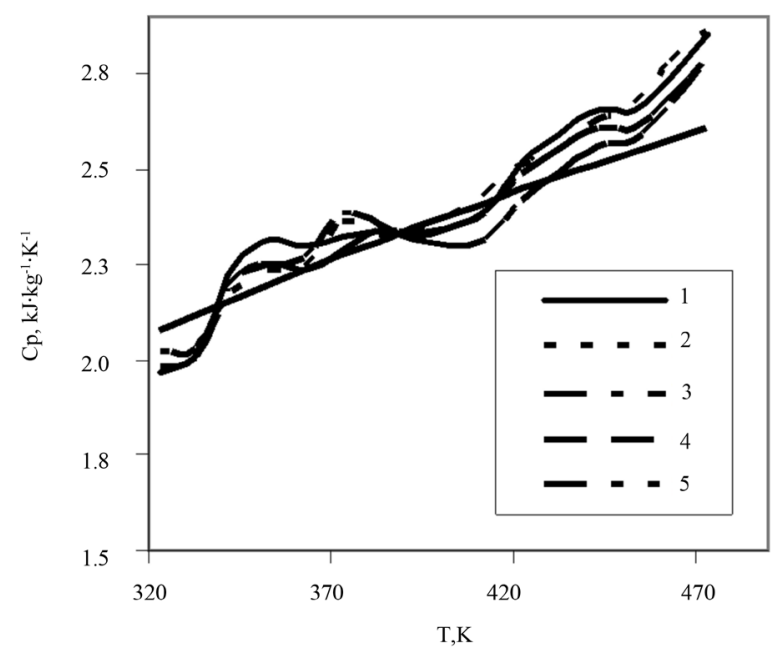

Figure 6. Heat capacity of the oil (sample No.2) at various pressures: $1-P=0.098 \mathrm{MPa}$; $2-P=9.8 \mathrm{MPa}$; $3-P=19.6$ $\mathrm{MPa}$; 4-P = 29.4 MPa; 5-calculation according to [65]-[67].

and Figure 5). The temperature dependences include phase transition regions. For example there are two such regions in Figure 1: the first (more evident) in the range of $350-420 \mathrm{~K}$, the second (narrower) in the range of $\sim 430-460 \mathrm{~K}$. As for the asphalt (Figure 4) and bitumen (Figure 5) there are more than two such regions. Similar patterns have been observed previously for the samples of crude oil and bitumen [37]-[42]. Such behavior according to [39] is explained by the presence of two phases of asphaltenes, one of which melts or vitrifies (endothermic effect), and the other one dissolves in the first phase (exothermic effect). For example, in [39] the discovery of 4 phases is noted.

Different methods of oil-products' heat capacity calculation have been analyzed: group component method, thermodynamic similarity method and empirical equations. All these methods have a common feature-they all require data on composition, structure and properties to calculate the heat capacity. In many cases, especially for multi-component compounds, such information is not available. According to the obtained data on elemental and structural composition of oil-products the computational methods have been analyzed, which require a minimum of information on the example of oil sample No.1. The results of calculations according to [52] [65]-[67] [73] and their comparison are presented in Figure 1. This figure shows that the smallest deviations of specific heat are calculated by methods of Shaw [65]-[67] and Filippov [73]. For the calculations by the method of Shaw [65]-[67] the elemental composition data (Table 1) have been used, while for the calculations by the method of Filippov [73] — the data on the content of saturated and aromatic hydrocarbons [43] [44] and molecu- 
lar weight (Table 2). The calculation method [52] gives much lower results (Figure 1), since it is not intended for heavy oils and bitumen. Thus, the method of calculation in [65]-[67] allows estimating the heat capacity values with the smallest error on the basis of minimal information. To analyze the phase behavior of oil there has been used an approach based on the calculation of excess heat capacity, which represents the difference between the measured heat capacity and heat capacity of the solid phase [38] [65]-[67]. Elemental composition data is used for the calculations. Based on the elemental analysis (Table 1), thermal capacities of solid phases and the excess heat capacities have been calculated for the oil-products (Figure 7). This figure shows both endothermic and exothermic effects. Similar dependences have been built for the oil (sample No.2), measured under pressure (Figure 2 and Figure 8). As can be seen from these figures the pressure has no significant effect on phase behavior.

As a result, it is found that the phase behavior is greatly influenced by temperature and composition of the oil. Pressure has no significant effect on behavior of the specific heat of the oil.

\subsection{Thermal Expansion Coefficient}

Experimental apparatus [54] has been applied for the measurement of $\alpha_{p}$ thermal expansion coefficient of the oil (sample No.2) at temperatures $T=298$ - $363 \mathrm{~K}$ and pressures up to $50 \mathrm{MPa}$ with an accuracy of $\pm 2 \%$. Results of the measurements are presented in Figure 9.

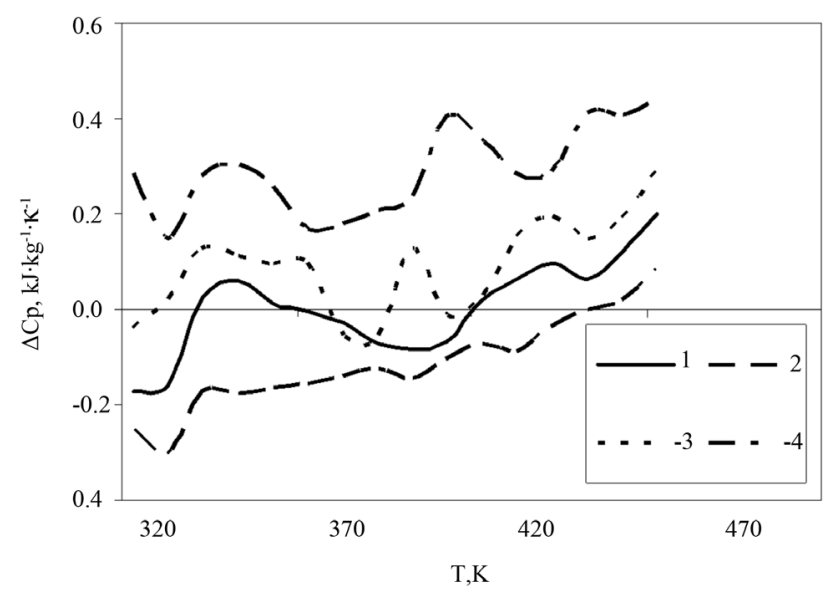

Figure 7. Excess heat capacity of the oil and oil-products: 1 - oil (sample No.1); 2-deasphaltizate; 3-asphalt; 4-bitumen.

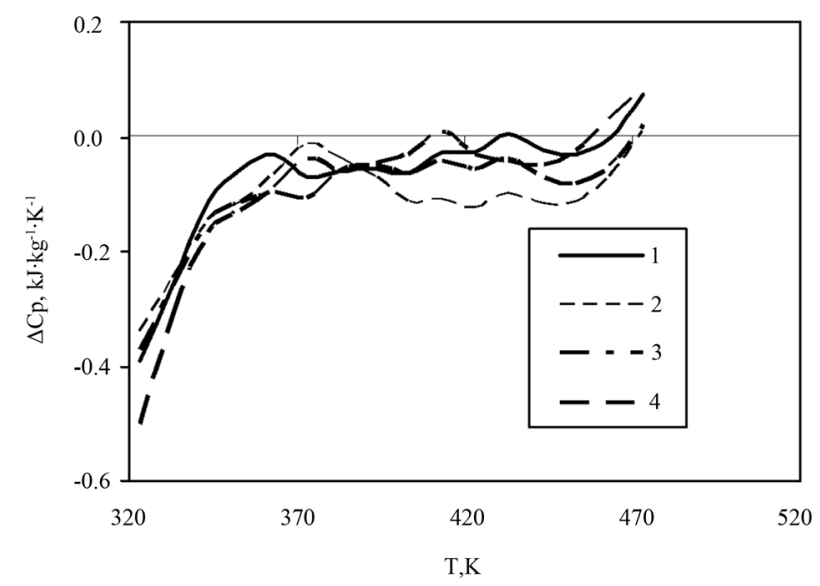

Figure 8. Excess heat capacity of the oil (sample No.2) at various pressures: $1-P=0.098 \mathrm{MPa} ; 2-P=9.8 \mathrm{MPa}$; $3-P=19.6 \mathrm{MPa}$; $4-P=29.4 \mathrm{MPa}$. 
Experimental data on $\alpha_{p}=f(p, T)$, obtained in a wide range of state parameters, allow estimation of the change patterns of $\alpha_{p}$ depending on temperature and pressure.

At temperatures $298 \mathrm{~K}$ and $303 \mathrm{~K}$ with the increase of pressure up to $25 \mathrm{MPa} \alpha_{p}$ first increases and then decreases. As for the other isotherms throughout the whole range of pressures a gradual decrease in thermal expansion coefficient can be observed. It should be noted that at a pressure of $25 \mathrm{MPa}$ an intersection of $\alpha_{p}$ isotherms occurs. Such behavior has been already noted [54] for n-hexane, where the intersecting point is near 70 MPa.

The results of the thermal expansion coefficient measurements have been applied for the calculation of density by using the following equation:

$$
\rho(P, T)=\rho\left(P, T_{R}\right) \exp \int_{T_{R}}^{T} \alpha_{P} \mathrm{~d} t
$$

where $\rho(P, T)$ and $\rho\left(P, T_{R}\right)$ —density of oil at pressure $P$ and temperatures $T$ and $T_{R}, \mathrm{~kg} \cdot \mathrm{m}^{-3} ; T_{R}$-reference temperature for the experiments, equal to $323 \mathrm{~K}$. Density values $\rho(P, T)$ and $\rho\left(P, T_{R}\right)$ are presented in Table 4.



Figure 9. Pressure dependence of the thermal expansion coefficient at various temperatures $T$, $\mathrm{K}$ (continues lines-smoothed-out data, dots-experiment): $1-T=$ $298 \mathrm{~K} ; 2-T=303 \mathrm{~K} ; 3-T=323 \mathrm{~K} ; 4-T=348 \mathrm{~K} ; 5-T=363 \mathrm{~K}$.

Table 4. The results of the density measurements and calculation $\left(\mathrm{kg} \cdot \mathrm{m}^{-3}\right)$.

\begin{tabular}{cccccc}
\hline \multirow{2}{*}{ Pressure P, MPa } & \multicolumn{5}{c}{ Temperature T, K } \\
\cline { 2 - 6 } & 298 & 303 & 323 & 348 & 963 \\
\hline 0.098 & 953.4 & 950.9 & 940.4 & 926.0 & 916.8 \\
9.8 & 963.9 & 961.3 & 950.7 & 936.9 & 928.4 \\
19.6 & 970.7 & 968 & 957.3 & 944.2 & 936.2 \\
29.6 & 975.8 & 973.1 & 962.4 & 949.7 & 942.2 \\
39.2 & 981.6 & 978.8 & 968.3 & 955.9 & 948.7 \\
49 & 990.1 & 987.5 & 977.3 & 965.1 & 957.8 \\
\hline
\end{tabular}




\section{Conclusions}

On the basis of structural analysis (Table 1) and measurements of density, refraction, and kinematic viscosity (Figure 1, Table 2) such molecular characteristics as molecular weight and similarity criterion of oil and oil products have been calculated (Table 3).

It was found that characteristics of the oil samples corresponded to fractions of bitumen oil with an average molecular weight of $465 \mathrm{~g} \cdot \mathrm{mol}^{-1}$. These fractions are characterized by a large number of high-molecular pentacyclic structures of C27-C35 composition. Adianthan C29 and Hopane C30 have the highest concentrations. The presence of solids in the composition of oil and its products is confirmed by the behavior of specific heat (melting/glass and dissolution peaks) (Figure 1 and Figures 4-6). Analysis of different methods for calculation of oil heat capacity (the method of group components, thermodynamic similarity and empirical equations) showed that the smallest deviations of specific heat were obtained by the methods of Shaw [65]-[67] and Filippov [73]. Calculation method [52] gives much lower results (Figure 1), since it is not intended for heavy oils and bitumen. Thus, the calculation method [65]-[67] allows us to estimate the values of heat capacity with the smallest error on the basis of minimal information. Analysis of phase behavior of the oil products, based on calculation of excess heat capacity representing the difference between the measured heat capacity and heat capacity of the solid phase [38] [65]-[67] has showed (Figure 7) the presence of areas with both endothermic and exothermic effects. As it can be seen from these figures, pressure has no significant effect on the phase behavior.

\section{Acknowledgements}

The research has been carried out in Kazan National Research Technological University with the financial support of government represented by the Ministry of Education and Science of Russian Federation. Agreement No.14.574.21.0085. Project's unique identifier RFMEFI57414X0085.

\section{References}

[1] Speight, J.G. (1981) The Desulfurization of Heavy Oils and Residua. Marcel Dekker, New York.

[2] Ancheyta-Juarez, J., Betancourt-Rivera, G., Marroquin-Sanchez, G., Perez-Arellano, A.M., Maity, K., Cortez, Ma.T., et al. (2001) An Exploratory Study for Obtaining Synthetic Crudes from Heavy Crude Oils via Hydrotreating. Energy Fuel, 15, 120-127. http://dx.doi.org/10.1021/ef000141m

[3] Ortega, R., Loria, A. and Kelly, R. (1995) A Semiglobally Stable Output Feedback PI2D Regulator for Robot Manipulators. IEEE Transactions on Automatic Control, 40, 1432-1436. http://dx.doi.org/10.1109/9.402235

[4] Babadagli, T. and Al-Bemani, A. (2007) Investigations on Matrix Recovery during Steam Injection into Heavy-Oil Containing Carbonate Rocks. Journal of Petroleum Science and Engineering, 58, 259-274. http://dx.doi.org/10.1016/j.petrol.2007.01.003

[5] Pineda-Perez, L.A., Carbognani, L., Spencer, R.J., Maini, B. and Pereira-Almao, P. (2010) Hydrocarbon Depletion of Athabasca Core at Near Steam-Assisted Gravity Drainage (SAGD) Conditions. Energy Fuels, 24, 5947-5954. http://pubs.acs.org/doi/abs/10.1021/ef100763j http://dx.doi.org/10.1021/ef100763j

[6] Liu, X., Zhao, G. and Jin, Y.C. (2006) Coupled Reservoir/Wormholes Model for Cold Heavy Oil Production Wells. Journal of Petroleum Science and Engineering, 50, 258-268. http://dx.doi.org/10.1016/j.petrol.2005.11.003

[7] Moghadam, S., Nobakht, M. and Gu, Y.A. (2009) Theoretical and Physical Modeling of a Solvent Vapor Extraction (VAPEX) Process for Heavy Oil Recovery. Journal of Petroleum Science and Engineering, 65, 93-104. http://dx.doi.org/10.1016/j.petrol.2008.12.029

[8] Barillas, J.L.M., Dutra Jr., T.V. and Mata, W. (2006) Reservoir and Operational Parameters Influence in SAGD Process. Journal of Petroleum Science and Engineering, 54, 34-42. http://dx.doi.org/10.1016/j.petrol.2006.07.008

[9] Petrobank Energy and Resources Ltd. www.petrobank.com

[10] Kurochkin, A.K. and Toptigin, S.P. (2012) Syntheric Oil. Residue Processing Technology for Russian Heavy Oils. Oil and Gas Refinery, 1, 92-105.

[11] Muslimov, R.K., et al. (2012) Integrated Development of Heavy Oils and Natural Bitumen of Permian System in Republic of Tatarstan. Fan Publishers, Kazan.

[12] Solodova, N.L. and Terentyeva, N.A. (2012) Current Status and Trends in Development of Catalytic Cracking of Petroleum Feedstock. Bulletin of Kazan Technological University, 15, 141-147.

[13] Khisamov, R.S., Gatiatullin, N.S. and Shargorodskiy, I.E. (2007) Geology and Development of Natural Bitumen Re- 
serves in Republic of Tatarstan. Fan Publishers, Kazan.

[14] Producing of Fuels from Natural Bitumen and Oil Shale. http://www.potram.ru/index.php?page=50

[15] Khadgiev, S.N. and Kadiev, H.M. (2011) A Method for Preparing of Heavy Hydrocarbon Feedstock for Thermal or Thermal-Catalytic Destruction. Patent of Russian Federation No. 2412230.

[16] Khadgiev, S.N. and Kadiev, H.M. (2010) A Method for Hydrogenation of Heavy Oil Residue. Patent of Russian Federation No. 2400525.

[17] Khadgiev, S.N. (2011) Nano-Heterogeneous Catalysis-A New Sector of Nanotechnology in Chemistry and PetroChemistry. Petrochemistry, 51, 3-16.

[18] Lu, Y., Tan, L., Czhao, S. and Chzhao, F. (2012) Study of Catalytic Aqua-Thermolysis of Heavy Oil in the Presence of a Hydrogen Donor. Chemistry and Technology of Fuels and Oils, 4, 16-21.

[19] Kayukova, G.P., Abdrafikova, I.M. and Petrov, S.M. (2012) International Scientific-Practical Conference "Highly Viscous Oil and Natural Bitumen: Problems and Improving the Efficiency of Exploration and Development”.

[20] Kun, C., Chen, Y., Li, J., Zhang, X. and Dong, B. (2012) Upgrading and Visbreaking of Super-Heavy Oil by Catalytic Aquathermolysis with Aromatic Sulfonic Copper. Fuel Processing Technology, 104, 174-180. http://dx.doi.org/10.1016/j.fuproc.2012.05.010

[21] Kayukova, G.P., Petrov, S.M. and Romanov, G.V. (2012) The Use of Hydrogenation Processes to Produce White Oils of Heavy Oil Deposits from Ashalchinskoye Accumulation. Technology of Fuels and Oils, 4, 9-15.

[22] Sirayev, R.F., Petrov, S.M., Kayukova, I.I., Vandukova, I.I. and Romanov, G.V. (2011) Preparation of Modified Bitumen Based on Heavy Oil Vacuum Residue from Ashalchinskoye Accumulation. Bulletin of Kazan Technological University, 9, 196-200.

[23] Sultanov, F.M. and Khayrutdinov, I.R. (2001) Petroleum Refinery and Petrochemistry.

[24] Farakhov, M.I., Kirichenko, S.M., Burmistrov, D.A. and Farakhov, M.M. (2009) A Method for Producing of Unoxidized Bitumen. Patent of Russian Federation No. 2371468.

[25] Fatkullin, A.A. (2000) The Impact of Gas Methods in the Development of Stranded Oil. Oil Industry, 1, 32-33.

[26] Starshov, M.I., Sitnikov, N.N. and Malyain, V.I. (1998) Technology for Intensification of Oil Producing and EOR and the Role of Super-Technologies. Science Publishers, Moscow.

[27] Surguchev, M.L. (1985) Secondary and Tertiary Methods for Enhancement of Oil Recovery. Nedra Publishers, Moscow.

[28] Gumerov, F.M. (2011) Prospects for the Use of Carbon Dioxide for Enhancement of Oil Recovery. News of Gas Science, 2, 93-109.

[29] Shakhverdiyev, A.K., Panakhov, G.M., Abbasov, E.M., Yang, R. and Bakhtiyarov, S. (2014) Highly-Effective Technology to Enhance Oil Recovery and Oil Production Intensification on the Basis of In Situ Generation of $\mathrm{CO}_{2}$. Oil Industry, 5, 90-95.

[30] Evdokimov, I.N. (2008) Training Manuals for the Master’s Program “Oil-Gas Nanotechnologies for the Development and Exploitation of Accumulations.” Part 4. Oils Incompatibility Problems While Mixing: Textbook, Russian State University of Oil and Gas, Moscow.

[31] Brusilovskiy, A.I. (2002) Phase Transitions at the Development of Oil and Gas Accumulations. Graal Publisher, Moscow.

[32] Valter Antonio, M.B., Ali Mansoori, G., De Almeida Xavier, L.C., Park, S.J. and Manafi, H. (2001) Asphaltene Flocculation and Collapse from Petroleum Fluids. Journal of Petroleum Science and Engineering, 32, 217-230. http://dx.doi.org/10.1016/S0920-4105(01)00163-2

[33] Abedi, S.J., Cai, H.Y., Seyfaie, S. and Shaw, J.M. (1999) Simultaneous Phase Behavior, Elemental Composition and Density Measurement Using X-Ray Imaging. Fluid Phase Equilibria, 160, 775-781. http://dx.doi.org/10.1016/S0378-3812(99)00109-0

[34] Chambion, P., Bertau, R. and Ehrburger, P. (1996) Characterization of Bitumen by Differential Scanning Calorimetry. Fuel, 75, 144-148. http://dx.doi.org/10.1016/0016-2361(95)00178-6

[35] Chen, J., Zhang, J. and Li, H. (2004) Determining the Wax Content of Crude Oils by Using Differential Scanning Calorimetry. Thermochimica Acta, 410, 23-26. http://dx.doi.org/10.1016/S0040-6031(03)00367-8

[36] Ganeyeva, Y.M. (2006) The Method of Differential Scanning Calorimetry in the Study of Oil Disperse Systems. Proceedings of the 6th International Conference on Gas and Petroleum Chemistry, Tomsk, 6-9 September 2006, 89-82.

[37] Zhang, Y., Takanohashi, T., Sato, S. and Saito, I. (2004) Observation of Glass Transition in Asphaltenes. Energy \& Fuels, 18, 283-284. http://dx.doi.org/10.1021/ef0301147

[38] Fulem, M., Beccera, M., Anwarul Hazan, M.D., Zhao, B. and Shaw, J.M. (2008) Phase Behaviour of Maya Crude Oil 
Based on Calorimetry and Rheometry. Fluid Phase Equilibria, 272, 32-41. http://dx.doi.org/10.1016/j.fluid.2008.06.005

[39] Maham, Y., Chodakowski, M.G., Zhang, X. and Shaw, J.M. (2005) Asphaltene Phase Behavior: Prediction at a Crossroads. Fluid Phase Equilibria, 227, 32-41. http://dx.doi.org/10.1016/j.fluid.2004.11.004

[40] Kariznovi, M., Nourozieh, H. and Abedi, J. (2011) Experimental Apparatus for Phase Behavior Study of Solvent-Bitumen Systems: A Critical Review and Design of a New Apparatus. Fuel, 90, 536-546. http://dx.doi.org/10.1016/j.fuel.2010.10.019

[41] Bagheri, S.R., Masik, B., Arboleda, P., Wen, Q., Michaelian, K.H. and Shaw, J.M. (2012) Physical Properties of Liquid Crystals in Athabasca Bitumen Fractions. Energy and Fuels, 26, 4978-4987. http://dx.doi.org/10.1021/ef300339v

[42] Tran, K.Q. (2009) Reversing and Non-Reversing Phase Transitions in Athabasca Bitumen Asphaltenes. Master's Thesis, University of Alberta, Edmonton.

[43] Zaidullin, I.M. (2013) Redistribution of Asphaltene Fractions under the Destabilization of Oil Dispersed Systems. Synopsis. Master's Thesis.

[44] Zaidullin, I.M., Petrova, L.M., Abbakumova, N.A. and Foss, T.R. (2011) The Composition of Heavy Oils and the Structural Characteristics of Components such as Factors Affecting the Stability of the Oils in the Precipitation of Asphaltenes. Bulletin of Kazan technological University, 10, 152-154.

[45] Gussamov, I.I., Petrov, S.M., Ibragimova, D.A., Kayukova, G.P. and Bashkirtseva, N.Y. (2014) Component and Hydrocarbon Composition of Bituminous Oil from Ashalchinskoye Accumulation. Bulletin of Kazan Technological University, 17, 207-211.

[46] Petrov, S.M., Khalikova, D.A., Abdelsalam, Y.I., Zakieva, R.R., Kayukova, G.P. and Bashkirtseva, N.Y. (2013) Perspectives of Hhighly-Viscous Oils of Ashalchinskoye Accumulation. Bulletin of Kazan Technological University, 16, 261-265.

[47] Petrukhina, N.N. (2014) Regulation of Transformation Components High Oil during Their Preparation for Transport and Processing. Master's Thesis, Moscow.

[48] Cherkasova, E.I. and Safiullin, I.I. (2015) Patterns for Development of High-Viscous Oils. Bulletin of Kazan Technological University, 18, 105-106.

[49] Rastorguev, Y.L., Grigor’ev, B.A., Ganiev, Y.A. and Andolenko, R.A. (1976) Experimental Investigation of Heat Capacity of Samotlor Crude Oil and Cuts from This Crude. Chemistry and Technology of Fuels and Oils, 12, 75-77. http://dx.doi.org/10.1007/bf00719057

[50] Elam, S.K., Tokura, I., Saito, K. and Altenkirch, R.A. (1989) Thermal Conductivity of Crude Oils. Experimental Thermal and Fluid Science, 2, 1-6. http://dx.doi.org/10.1016/0894-1777(89)90043-5

[51] Magomadov, A.S. (2004) Viscosity and Thermal Conductivity of Heavy Oils in the Region of High Temperatures and Pressures. Thermo Physics of High Temperatures, 42, 243-246. http://dx.doi.org/10.1023/b:hite.0000026155.07262.11

[52] Grigor'yev, B.A., Bogatoye, G.F. and Gerasimov, A.A. (1999) Thermophysical Properties of Oil, Oil-Products, Gas Condensates and Their Fractions. Moscow Power Engineering University, Moscow.

[53] Grigor'ev, V.A. and Svidchenko, A.I. (1980) Effect of Pressure on Thermal Conductivity of Crude Oils and Products. Fuel and Lubricant Quality Evaluation Methods. Chemistry and Technology of Fuels and Oils, 16, 131-134. http://dx.doi.org/10.1007/BF00730228

[54] Zaripov, Z.I., Burtsev, S.A., Gavrilov, A.V. and Mukhamedzyanov, G.K. (2002) Thermal Properties of $n$-Hexane at Temperatures of 298.15-363.5 K and Pressures of 0.098-147 MPa. Theoretical Foundations of Chemical Engineering, 36, 400-405. http://dx.doi.org/10.1023/A:1019864119650

[55] Zaripov, Z.I., Burtsev, S.A., Gavrilov, A.V. and Mukhamedzyanov, G.K. (2004) Determination of the Thermophysical Properties of Halogenated Hydrocarbons in a Heat-Conducting Calorimeter. High Temperature, 42, 282-289. http://dx.doi.org/10.1023/b:hite.0000026165.64827.3d

[56] Zaripov, Z.I., Burtsev, S.A., Bulaev, S.A. and Mukhamedzyanov, G.K. (2004) The Heat Capacity and Thermal Diffusivity of Aqueous Solutions of Alkali Metal Salts in a Wide Pressure Range. Journal of Physical Chemistry, 78, 697700.

[57] Zaripov, Z.I. and Mukhamedzyanov, G.K. (2008) Thermophysical Properties of Liquids and Solutions. Kazan State Technological University, Kazan.

[58] Zaripov, Z.I., Burtsev, S.A., Gavrilov, A.V., Bulaev, S.A. and Mukhamedzyanov, G.K. (2002) Thermal and Caloric Properties of $n$-Butyl Alcohol. Bulletin of Kazan Technological University, 1, 208-212.

[59] Government Standard GOST 18995.1-73. Liquid Chemicals. Methods for Density Determination.

[60] Government Standard GOST 22524-77. Glass Pycnometers. Technical Conditions. 
[61] Government Standard GOST 10028-81. Glass Capillary Viscometers. Technical Conditions.

[62] Government Standard GOST 18995.2-73. Liquid Chemicals. Methods for Refraction Index Determination.

[63] Government Standard GOST 3516-74. A Method for Measurement of Refraction and Dispersion Indexes Using Refractometer.

[64] http://additive.spb.ru/molecular-mass.html

[65] Lastovka, V., Fulem, M., Becerra, M. and Shaw, J.M. (2008) A Similarity Variable for Estimating the Heat Capacity of Solid Organic Compounds Part II. Application: Heat Capacity Calculation for Ill-Defined Organic Solids. Fluid Phase Equilibria, 268, 134-141. http://dx.doi.org/10.1016/j.fluid.2008.03.018

[66] Lastovka, V., Sallamie, N. and Shaw, J.M. (2008) A Similarity Variable for Estimating the Heat Capacity of Solid Organic Compounds Part I: Fundamentals. Fluid Phase Equilibria, 268, 51-60. http://dx.doi.org/10.1016/j.fluid.2008.03.019

[67] Lastovka, V. and Shaw, J.M. (2007) Predictive Correlation for Cp of Organic Solids Based on Elemental Composition. Journal of Chemical Engineering, 52, 1160-1164.

[68] Government Standard GOST 25371-97. Oil-Products. Calculation of Viscosity Index Using Kinematic Viscosity.

[69] Usmanov, R.A., Shamsetdinov, F.N., Gabitov, R.R., Biktashev, S.A., Gumerov, F.M., Gabitov, F.R., et al. (2011) Pilot Plant for the Continuous Transesterification of Vegetable Oils in Supercritical Ethanol and Methanol Medium. Supercritical Fluids: Theoryandpractice, 2, 1-19.

[70] Shamsetdinov, F.N., Zaripov, Z.I., et al. (2012) High Yield Biofuel Production from Vegetable Oils with Supercritical Alcohols. Nova Science Publishers, New York.

[71] Vasil'yev, I.A. and Petrov, V.M. (1984) Thermodynamic Properties of Oxygenated Organic Compounds. Handbook, Chemistry, Saint Petersburg.

[72] Naziyev, Y.M., Shakhverdiyaev, A.N., Bashirov, M.M. and Aliyev, N.S. (1994) Thermal Properties of Single-Atom Alcohols (Isobaric Heat Capacity). Thermo Physics of High Temperatures, 32, 936-937.

[73] Shakhparonov, M.I. and Phillipov, L.P. (1989) Liquid Hydrocarbons and Oil-Products. Moscow State University, Moscow. 